\title{
Formation of Risk-balanced Style of Professional Activity among University Students
}

\author{
Natalia Kuzhanova \\ Department of Engineering and \\ Construction TechnologiesPskov State \\ University \\ Pskov, Russia \\ natalya_kuzhanova@mail.ru
}

\author{
Alexander Dementiev \\ Department of Engineering and Con- \\ struction Technologies \\ Pskov State University \\ Pskov, Russia \\ damix01@yandex.ru
}

\author{
Tatyana Klets \\ Department of Russian Philology and \\ Foreign Languages \\ Pskov State University \\ Pskov, Russia \\ kte63@yandex.ru
}

\begin{abstract}
The basis of the sustainable development of society with ever-growing scientific and technical progress is noxology as a science about the dangers of the world, since the risk of being in modern society is higher than ever. In this regard, a scientific noxospheric picture of the world is being formed as an integrative knowledge system, which should be the basis for the formation of a new, noxological worldview, in which security is the main value norm of riskoriented thinking. The article is aimed at the theoretical substantiation of the necessity of dev+eloping a risk-balanced style of professional activity among university students on the basis of risk-thinking as an objective property of the personality. The article also reveals the authors' concept of the noxological consciousness and explains the term of a risk-balanced style of professional activity. The definition, structure and main constituent elements of this personal phenomenon are given. It is determined that noxological style of professional activity includes such components as risk-thinking, self-regulation, intellectual features and capabilities, "labor model", individual biological rhythms, will, as well as habits and special techniques of activity. Various characteristics of risks in the professional activity of a specialist are considered. Based on the analysis of scientific and pedagogical literature on the problem and the method of observation, the modeling of the pedagogical system of training a specialist with a risk-balanced style of professional activity is presented, the effectiveness of which is confirmed by the formative experiment.
\end{abstract}

Keywords-noxological consciousness, risk-balanced style of professional activity, risk-thinking, technospheric safety expert

\section{INTRODUCTION}

It is believed that the reproduction system of a new, sixth technological order is currently being formed in the economy, the formation and growth of which will determine global economic development in the next two to three decades. The intellectualization of production will continuously increase, the transition to a continuous innovation process in most industries and continuous education in most professions will be realized [1]. Great importance will be attached to the quality of life and comfort of the habitat. Among the current professions will be those that will directly form this most comfortable environment. There are, among others, an urban ecologist, an ecology preacher, and a specialist in overcoming systemic environmental disasters.

According to the Atlas of New Professions [2], an urban ecologist will design new environmentally friendly cities, an environmental preacher will form an environmentally conscious lifestyle, conduct educational programs on relevant topics for different age groups. A specialist in overcoming systemic environmental disasters is designed to prevent disasters that people gradually realize, namely: pollution around industrial centers, radiation waste, melting glaciers, etc. Thus, civilizational changes, change of cultural-value and scientific-educational paradigms become inevitable and feasible in a fairly foreseeable future. The technosphere as a human habitat that has arisen as a result of direct or indirect anthropogenic impact, aimed at meeting the socio-economic and physiological needs of man, must consistently undergo changes based on the rationalization of material and energy processes to ensure the sustainability of civilization [3].

The basis of sustainable development with everincreasing scientific and technical progress, in turn, is noxology. Noxology is known to be the science of the dangers of the world, since the risk of being in modern society is higher than ever. It seems reasonable to believe that a scientific noxospheric picture of the world as an integrative knowledge system is currently being formed [4]. It should be the basis for the formation of a new noxological consciousness, in which safety is the main value norm and risk-based thinking. The subject of our article is the noxological consciousness, risk-thinking and the risk-balanced style of professional activity based on it as the objective characteristics of the personality of a future specialist and a member of the society.

\section{Materials And Methods}

Before considering the indicated phenomena of personality their definitions should be determined. It is considered that risk-thinking is the process of reflecting objective reality in conclusions, concepts, judgments, in which danger and risk as an objective factor of life are evaluated and analyzed [1].

Following the meaning of this definition it is most Online ISSN 2256-070X

http://dx.doi.org/10.17770/etr2019vol1.4034 (C) 2019 Natalia Kuzhanova, Alexander Dementiev, Tatyana Klets. Published by Rezekne Academy of Technologies.

This is an open access article under the Creative Commons Attribution 4.0 International License. 
expedient to consider such a personal phenomenon in which relationship with the environment will be built in such a way that the risks of being would not potentially carry tangible threats or would be detected and eliminated in a timely manner in the process of building individual life scenarios. Thus, it seems that risk-thinking should be linked in disclosing the genesis of professional individuality with the noxological style of professional activity.

To substantiate this position the following arguments should be presented. In scientific and artistic literature, attention has repeatedly been drawn to the changes that occur with a person in the process of mastering and carrying out a long-term performance of any activity. These changes occur on the psychophysiological, mental and personal levels: the higher the professional skills, the more confident the personality. These changes are gradually reflected in common external manifestations (motility, speech, emotionality, speech, etc.). At a deeper personal level, the formation of the corresponding elements of professional consciousness (professional attention, perception, memory, thinking, emotional sphere) takes place. In a broader context, we can talk about the development of a professional worldview, changes in the relevant components of the subject in relation to the object of activity. This is manifested in the cognitive sphere (the level of awareness of the object, the degree of awareness of its importance); in the emotional sphere (interest in the object), in the inclination and satisfaction from interacting with it; in the practical field.

It is believed that in the process of becoming a professional a spontaneous restructuring of the personality takes place, which should be used to provide optimal assistance to the future professional, to give this process a meaningful character [5].

It's obvious that the period of life in the student's age, when the processes of reflection are most mobile and qualitative personal-professional changes occur, is the optimal time for an organic connection of the professionalnoxological worldview and their translation into personal values and life orientations.

In this connection, the concept of an individual style of activity is used, on which a risk-balanced style of professional activity will be built.

Thus, an individual style of activity is understood as a self-developing, and, therefore, periodically changing system of techniques and methods of activity, the strategy of which is determined by the typological features of the nervous system and temperament, and the tactics of its performance are provided by the unique combination of strong-willed, intellectual and emotional qualities consciously selected and fixed individual in the process of its development.

In the context of risk-balanced thinking in the noxological style of professional activity, the following components of its structure can be distinguished:

- risk reflection;

- self-regulation;

- intellectual features and capabilities;

- "model of labour";

- individual biological rhythms;

- will;
- habits and special techniques of professional activities.

The backbone element is risk reflection, and the elements indirectly associated with it and each other are all the other elements represented in the structure. Below are the characteristics of the coordinated elements of the style of activity and in more detail risk-reflection as the basis for the risk-balanced style of professional activity.

Intellectual features and capabilities of a person are associated with such characteristics as the degree of development of intellectual capabilities, the dominant type of thinking, the volume and features of memory, the individual's leading modality, etc. The "model of labor" is associated with the manifestation of the external dynamic aspect of human activity, its "unique pattern" of activity (continuous intellectual offensive, flexible switching, rhythmic periodization method, etc.). It is the "labour model" that is the typical side, which is based on the individual characteristics associated with the first level of the integral individuality of a person. They can be called styles that provide the first adaptive effect to the conditions of activity, and characterize them as typical styles inherent to the groups of persons within which that unique and strictly individual set of techniques and methods exists that constitutes a true individual style. Thus, the "model of labour" is deeply individual, and at the same time typical for a group of people with a similar type of nervous system and temperament. It is individual because it is associated with individual rhythms - periods of alternation of work and rest time. It is typical because a certain external form of behaviour is preserved.

Individual habits are also part of the system. They are caused by factors of a twofold kind: tastes, predilections, inclinations of a person and his social and material possibilities.

The technical techniques of intellectual activity include such features as the ability to read, observe and listen, taking into account various tasks, for example, the selection of the main from the secondary, speed reading, a quick scan, decoding of visual information, note-taking skills, etc. A set of these techniques will be different for each individual due to the individual and personal characteristics of perception, memory, thinking, skills, abilities, etc.

Of course, the above features of the style of activity manifest when this activity is performed without attributing it to the risk-balanced professional activity. But it is impossible to ignore these general patterns, since this is where the personality manifests itself in the concept of a systematic approach to it.

Such psychological phenomenon as the will of the individual requires special attention. The psychological phenomenon of the will somehow imperceptibly began to belong to the military and sports psychology and almost completely disappeared from the arsenal of classical science and pedagogy [6].

Many people today continue to demonstrate the ultimate achievements of personal courage, jumping from transcendental heights, plunging into the depths of the ocean, skiing down steeps, overcoming the World Ocean alone, soaring into space and suffering there for the sake of science. And these are all high risks of being and not always justified, but causing admiration and delight. But at the same time, the mass of people give up the slightest 
effort to start work in the morning, abandon fatal pleasures, force themselves to ponder over an unresolved question, imagine the prospect of their own life. And here, too, may be risks, but delayed or implicitly expressed, but, perhaps, from this no less high risks for the basics of being.

It should be stressed that forgetting the psychology of the will as an independent direction is wrong. The importance of the psychology of the will for a person is determined by the fact that without it, the use of coercion and self-coercion, self-control, self-regulation, selfeducation is impossible. All that "self" is will. "Self" is a mental effort that binds together the motive and action of a person. This effort can be applied to person's actions, and can be used to shape the actions of other people, which is no less important for the risk-balanced action. Without an act of will, no action is accomplished, no conscious action is performed. Any success by all means is based on a huge resource of volitional efforts for overcoming external and internal obstacles. Possession of high volitional qualities is the key to the success of anyone and everyone.

Risk-balanced activity and the formation of the noxological consciousness require the presence of will in a person, perhaps more than in anything else, since the noxological worldview implies a voluntary and conscious limitation of one's needs and purposeful activity often in unpopular and not always comfortable conditions.

The following definition is used for the noxological consciousness. Noxological consciousness is such a system of relations to objective reality, which: 1) relies on the post-non-classical paradigm of the development of science and society; 2) considers safety issues for a person, his surroundings, and society as a whole as priority ones; 3) forms a high motivational activity to overcome anthropogenic crises through development, when a higher level of dynamic equilibrium with the environment is established; 4) regards the noxological worldview as a compensating factor the ever-increasing instrumental and technological capabilities of a person, maintains internal control over the manifestation of the aggression of the society and each person.

Risk-reflection, as already mentioned, is a systemforming element, since it is precisely the form of theoretical human activity aimed at the activity of selfknowledge and understanding actions and laws. The degree of development of reflection determines a person's self-regulation and will functions. Subjective assessment of the situation and making decisions related to risks is one of the functions of reflection.

What is risk-reflection in the risk-oriented style of professional activity?

It is necessary to state that in the context of the problem considered in this article, the concept of "risk" is associated not only with professional activities, but also has a more general character. Risk, as a rule, is considered as the probability of danger manifestation, taking into account the possible extent of harm, as the possibility of implementing the worst alternatives [4]. Zero risk does not happen. But since the concept of "risk" originated and developed primarily in the field of economics and entrepreneurship [7] and was associated with activities carried out at your own risk in order to obtain material profits, the concept of risk has positive sense.

Risks associated with production activities, when there is a threat to the life or health of the worker or the risks of being associated with technospheric changes in the environment, have a correspondingly negative value. In this regard, it should be noted that the concept of acceptable risk is gaining momentum.

But there is one more concept of risk - "reasonable risk". In the Criminal Code of the Russian Federation, article 41, this concept is considered as an action associated with the risk of causing harm, but aimed at achieving a socially useful goal, and, therefore, is justified or necessary in any situation [8].

There is the concept of dialectically related risk in society, which constitutes a unity of opposites: when one activity associated with risks is responsible for the performance of activities, the achievement of a new planned result, for progress, and the other for the safety of activities, for the preservation of life, health, property, status, etc. Thus, for one person in carrying out activities the risk has two sides: the risk associated with the desire for good and the risk associated with the desire to avoid hazards and losses.

The task of training technosphere safety specialists is to prepare a specialist who has such skills consciously or ideally. These skills form an individual style of riskbalanced professional activity.

Why is such a wide range of risks necessary?

First of all, it is obvious that life, including professional life, is often very contradictory and unpredictable. Secondly, the risks of being are steadily increasing and we all need to be prepared for these challenges. Thirdly, the more multifaceted a person is, the more likely he is to adapt to a rapidly changing world. But in the context of this article, this means the following.

Experts in the field of technosphere safety work in various sectors of the economy. Working in the supervisory and control authorities for natural resources, environmental protection, as well as at enterprises in labour protection and safety structures, these specialists should evaluate the activities of other people and the associated risks in order to maximize the preservation of life, health, material values and natural resources in terms of acceptable risk.

If technosphere safety specialists are engaged in environmental business (green products and packaging, reuse of resources, etc.), then the risks arising as a result of thisactivity are quite conscious for getting profit in business [9]. Finally, if the activities of other people are assessed in a criminal procedural context, then it is necessary to objectively evaluate a reasonable risk. Thus, a specialist in the field of technosphere safety should have free will, ensuring him both the freedom of choice and freedom of action within professional competencies but with a conscious necessary and sufficient degree of responsibility for making professional decisions. This will is a part of the structure of his professional risk-balanced style of activity. 


\section{RESULTS AND DISCUSSION}

Pedagogical grounds for preparing students for riskbalanced activities as a pedagogical system are shown in Fig.1.

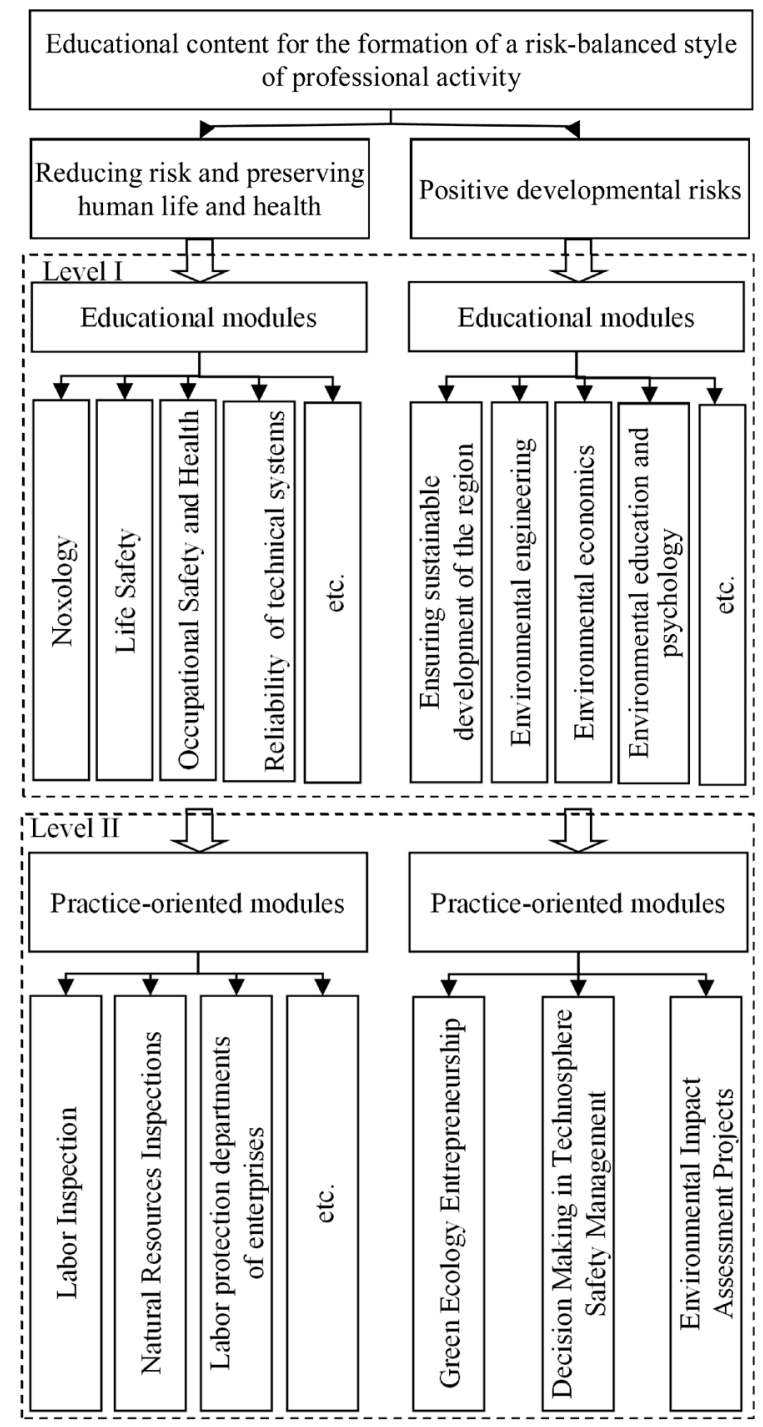

Fig.1.The block diagram of the model of education of a specialist in technosphere safety

The content of educational modules is aimed at the formation of a risk-balanced style of professional activity. For this purpose, the project method, case technologies and other educational technologies are used. These methodological instruments are aimed at the maximum possible independent work of students, the organization of their activities in solving the tasks set. In addition, purposeful work is under way to organize the interaction of students with specialists in the field of environmental protection, where a style of professional activity is formed, figuratively speaking in the first approximation.

Practice-oriented modules are aimed at improving the emerging professional activity. The practice reports of students include a section where it is necessary to analyze what types of risks are major during the passage of industrial and technological, production and organizational practices, when addressing issues of preproject environmental impact assessment or drafting an environmental impact assessment project.

\section{CONCLUSION}

In modern conditions, according to the concept of the noxospheric picture of the world, it is risk-thinking as an objective property of the personality of a future specialist and a member of society that forms the basis for the development of a risk-balanced style of professional activity among university students.

The formation of a specialist with a given set of qualities, including in the emotional-volitional sphere, is carried out in a specific environment of an educational institution, determined by many factors of a subjective and objective nature.

The phenomenon considered in the article is difficult to laboratory experiment, observation and description. In practical psychology at the moment there are no qualimetric characteristics for its description. These problems are beyond the scope of the discussed psychological phenomenon and are the subject of a separate study. For the time being, this phenomenon is estimated by indirect evidence of the correctness of making professional decisions in various areas of activity.

At Pskov State University, in preparing specialists for technosphere safety, in our opinion, the necessary pedagogical environment has been formed for the formation of a risk-balanced style of professional activity.

Graduates from the "Technosphere Safety" profile are almost $100 \%$ employed by the chosen profession. They work both in state environmental protection structures and in enterprises of various types of property. The quality of training is confirmed by the passage of professional certifications of various levels and rapid career growth.

\section{REFERENCES}

[1] N. E. Yegorov and G. S. Kovrov, "Features of personnel training in the conditions of transition to a new technological structure," Man and Education, vol.2, 2018, pp. 117-122.

[2] Atlas of new professions. [Online]. Available: http://www.atlas 100.ru. [Accessed: Dec.15, 2018].

[3] N. Kuzhanova and T. Klets, Methodological and psychological aspects of education for sustainable development in Russia with regard to international cooperation: Environment. Technology. Resources: Proceedings of the 11th International Scientific and Practical Conference, June 15-17, 2017, Rezekne, Latvia, vol. I, pp.165-168.

[4] A. A. Aleksandrov and V. A. Devyasilov, Conceptual and didactic foundations of education in the field of security: Proceedings of the Vth All-Russian Meeting of Heads of Chairs of Higher Educational Institutions on Education in the Field of Life Safety and Environmental Protection, September 30 - October 6, 2013. Moscow: MSTU named after N. E. Bauman, 2013, pp. 9-22.

[5] O.A. Lapina, "Formation of an individual style of professional activity of a teacher: methodology, theory, practice," Dr. of Sc. Thesis, Omsk State Pedagogical University Press, Omsk, 2002.

[6] A. I. Yuriev, "Modern problems of psychology: unexplored equivalents of objective reality," Bulletin of St. Petersburg University, Series 6, vol.1, 2014, pp. 95-197.

[7] A. G. Fedorets, "Concepts of risk in life and human activity," Safety in the Technosphere, vol. 1, 2013. [Online]. Available: http:// www.magbvt.ru. [Accessed: Dec.10, 2018].

[8] V. A. Akimov, Reliability of technical systems and technological risk. M.: ZAO FID Business Express, 2002, 368 p.

[9] N. I. Kuzhanova, Forming of ecological culture of students at the higher technical school. Pskov: POIPKRO, 2004, 292 p. 